CLINICAL STUDY

\title{
Sex-specific association of PTPN22 1858T with type 1 diabetes but not with Hashimoto's thyroiditis or Addison's disease in the German population
}

\author{
Heinrich Kahles*, Elizabeth Ramos-Lopez*, Britta Lange, Oliver Zwermann ${ }^{1}$, Martin Reincke ${ }^{1}$ \\ and Klaus Badenhoop \\ Department of Internal Medicine I, Division of Endocrinology, Diabetes and Metabolism, University Hospital Frankfurt, Theodor-Stern-Kai 7, D-60590 \\ Frankfurt am Main, Germany and ${ }^{1}$ Department of Internal Medicine, Division of Endocrinology and Diabetes, University Hospital Munich, Munich, \\ Germany \\ (Correspondence should be addressed to K Badenhoop; Email: badenhoop@em.uni-frankfurt.de)
}

*H Kahles and E Ramos-Lopez contributed equally to this study

\begin{abstract}
Background: Endocrine autoimmune disorders share genetic susceptibility loci, causing a disordered T-cell activation and homeostasis (HLA class II genes, CTLA-4). Recent studies showed a genetic variation within the PTPN22 gene to be an additional risk factor.

Materials and Methods: Patients with type 1 diabetes $(n=220)$, Hashimoto's thyroiditis $(n=94)$, Addison's disease $(n=121)$ and healthy controls $(n=239)$ were genotyped for the gene polymorphism PTPN22 $1858 \mathrm{C} / \mathrm{T}$.

Results: Our study confirms a significant association between allelic variation of the PTPN22 1858 $\mathrm{C} / \mathrm{T}$ polymorphism and type 1 diabetes mellitus (T1D). $1858 \mathrm{~T}$ was observed more frequently in T1D patients $(19.3 \%$ vs $11.3 \%, P=0.0009$; odds ratio for allele $\mathrm{T}=1.88,95 \%$ confidence interval $[1.3-2.7])$. Furthermore, we found a strong association in female patients with T1D $(P=0.0003)$, whereas there was no significant difference between male patients with type 1 diabetes and male controls. No significant difference was observed between the distribution of PTPN22 C/T in patients with Hashimoto's thyroiditis or Addison's disease and healthy controls.

Conclusion: The PTPN22 polymorphism $1858 \mathrm{C} / \mathrm{T}$ may be involved in the pathogenesis of type 1 diabetes mellitus by a sex-specific mechanism that contributes to susceptibility in females.
\end{abstract}

European Journal of Endocrinology 153 895-899

\section{Introduction}

Type 1 diabetes mellitus (T1D), Hashimoto's thyroiditis and Addison's disease are all caused by immune mediated self-destruction, where autoreactive cytotoxic T-lymphocytes appear to be the main effector cells $(1-3)$.

So far, several proteins have been identified with genetic susceptibilities to autoimmune diseases that are involved in T-cell interaction. As the key determinant of the T-cell response to antigens, human leukocyte antigen (HLA) molecules have shown unequivocal evidence for a role in the susceptibility to type 1 diabetes, Hashimoto's thyroiditis and Addison's disease (4-7). Furthermore, single nucleotide polymorphisms (SNPs) within the cytotoxic T lymphocyte antigen-4 (CTLA-4) gene have also been shown to confer susceptibility to these diseases in several populations $(8,9)$.

Recently, evidence for another susceptibility locus has been reported: the protein tyrosine phosphatase
N22 (PTPN22) gene (10). PTPN22 is localized on chromosome 1p13 encoding for the lymphoid-specific phosphatase (LYP), which is expressed in both immature and mature B- and T-cells (11). LYP is a powerful inhibitor of the T-cell antigen receptor signaling pathway. Thus, in conjunction with protein kinase Csk, LYP restricts the response to antigens by disrupting protein tyrosine phosphorylation events that control cell activation and differentiation. Subsequently, this negative control mechanism prevents spontaneous T-cell activations and reverts activated T-blasts to a resting phenotype (10).

The functional importance of LYP on susceptibility in autoimmune diseases was first implicated by Bottini et al. (10). They identified an SNP at nucleotide 1858 in codon 620 of PTPN22 that causes a substitution of arginine with tryptophan in the amino acid chain (10). In vitro experiments show that only LYP with Arg620 (allele 1858C) forms a complex with Csk whereas LYP with Trp620 (allele 1858T) binds less 
efficiently (12). Accordingly, the PTPN22 1858T allele raises the potential for a 'hyper-reactive' pathogenetic T-cell response (13).

This assumption is supported by large case-control and family studies, showing an association of $1858 \mathrm{~T}$ with susceptibility to autoimmune diseases such as type 1 diabetes (T1D), rheumatoid arthritis (RA), systemic lupus erythematosus (SLE) and Graves' disease (GD) $(10,12-17)$.

Given the growing evidence that PTPN22 is associated with autoimmunity in general, we analyzed the PTPN22 $1858 \mathrm{C} / \mathrm{T}$ polymorphism in German patients with type 1 diabetes, Addison's disease (AD) and Hashimoto's thyroiditis (HT).

\section{Subjects and methods}

\section{Subjects}

All patients were recruited from the endocrine outpatient clinics at the University Hospitals of Frankfurt am Main, Freiburg and Düsseldorf (Germany).

Altogether, 673 individuals (121 patients with AD, 94 patients with HT, 220 type 1 diabetic patients and 239 German healthy controls) were genotyped for the PTPN22 $1858 \mathrm{C} / \mathrm{T}$ polymorphism.

Addison's disease was diagnosed by primary adrenocortical insufficiency without evidence of tuberculosis or adrenoleukodystrophy. Adrenal autoantibodies were detected with indirect immunofluorescence on cryostat sections; in a subgroup of patients radioimmunoassay confirmed that these were directed against 21-hydroxylase. No neurological deficits could be detected.

The diagnosis of Hashimoto's thyroiditis was established by positive thyroglobulin and/or thyroid peroxidase antibodies, reduced echogenicity on thyroid ultrasound, and normal or elevated thyrotropin levels.

Type 1 diabetes was diagnosed according to World Health Organization criteria. The median age of disease onset was 10 years (range $1-44$ years).

Healthy controls (HC) were volunteer blood donors from the Red Cross Blood Transfusion Center in Frankfurt am Main (Germany), staff personnel or medical students from the University Hospital Frankfurt am Main (Germany) without a family history of type 1 diabetes mellitus, Hashimoto's thyroiditis, Graves' disease or Addison's disease. Although the adrenal function of the controls was not formally assessed, they had normal thyroid function and were thyroid autoantibody negative.

All individuals were of Caucasian origin and were inhabitants from the surrounding area of Frankfurt am Main (Germany). The male:female ratio of patients with AD, HT, T1D and HC was 1:2.2, 1:4.5, 1:1.1 and 1:0.8 respectively. The average ages (in years) of patients with AD, HT, T1D and HC were 57.4 16.0 (range 22-

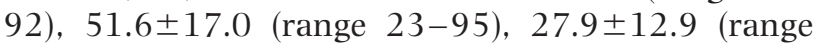
$6-69$ ) and $49.4 \pm 16.6$ (range $23-83$ ) respectively.

The study protocol was approved by the Ethics Committee of the University Hospital, Frankfurt am Main, and written informed consent was obtained from all patients and controls.

\section{Genotype analysis}

DNA was extracted from whole blood according to standard protocols. The PTPN22 $1858 \mathrm{C} / \mathrm{T}$ polymorphism (rs2476601) was analyzed by real-time PCR using the ABI 7300 (Applied Biosystems, Darmstadt, Germany). Primer and probe sequences were as follows: forward primer 5'-CAACTGCTCCAAGGATAGATGATGA-3'; reverse primer 5'-CCAGCTTCCTCAACCACAATAAATG-3'; probe for C allele, 5'-FAM-TCAGGTGTCC-

Table 1 Distribution of the PTPN22 $1858 \mathrm{C} / \mathrm{T}$ polymorphism in German healthy controls and patients with autoimmune endocrinopathies.

\begin{tabular}{|c|c|c|c|c|c|c|c|c|}
\hline & \multicolumn{2}{|c|}{$\begin{array}{l}\text { Controls } \\
(n=239)\end{array}$} & \multicolumn{2}{|c|}{$\begin{array}{l}\text { Type } 1 \text { diabetes } \\
(n=220)\end{array}$} & \multicolumn{2}{|c|}{$\begin{array}{c}\text { Addison's } \\
\text { disease }(n=121)\end{array}$} & \multicolumn{2}{|c|}{$\begin{array}{c}\text { Hashimoto's } \\
\text { thyroiditis } \\
(n=94)\end{array}$} \\
\hline & $n$ & $\%$ & $n$ & $\%$ & $n$ & $\%$ & $n$ & $\%$ \\
\hline \multicolumn{9}{|l|}{ Genotypes } \\
\hline CC & 187 & 78.2 & 142 & 64.5 & 96 & 79.3 & 67 & 71.3 \\
\hline CT & 50 & 20.9 & 71 & 32.3 & 22 & 18.2 & 25 & 26.6 \\
\hline TT & 2 & 0.8 & 7 & 3.2 & 3 & 2.5 & 2 & 2.1 \\
\hline$P^{1}$ & \multirow{2}{*}{\multicolumn{2}{|c|}{0.8753}} & \multirow{2}{*}{\multicolumn{2}{|c|}{$\begin{array}{l}0.0027 \\
0.9308\end{array}$}} & \multicolumn{2}{|c|}{0.3918} & \multicolumn{2}{|c|}{0.3119} \\
\hline$P(\mathrm{HWE})^{2}$ & & & & & & & & \\
\hline \multicolumn{9}{|l|}{ Allele } \\
\hline C & 424 & 88.7 & 355 & 80.7 & 214 & 88.4 & 159 & 84.6 \\
\hline $\mathrm{T}$ & 54 & 11.3 & 85 & 19.3 & 28 & 11.6 & 29 & 15.4 \\
\hline$P^{1}$ & & & \multicolumn{2}{|c|}{0.0009} & \multicolumn{2}{|c|}{0.9878} & \multicolumn{2}{|c|}{0.1863} \\
\hline OR $[95 \% \mathrm{CI}]^{3}$ & & & & 2.7] & 1.03 & .67] & 1.4 & ..33] \\
\hline
\end{tabular}

${ }^{1}$ Compared with controls; ${ }^{2} \mathrm{P}(\mathrm{HWE})$, probability of deviation of the observed from the expected genotype frequencies by chance; ${ }^{3}$ odds ratio for the $\mathrm{T}$ allele compared with controls [Cl, confidence interval]. 
GTACAGG-3'; probe for T allele 5'-VIC-TCAGGTGTCCATACAGG-3'.

The interaction analyses used the CTLA4 49 A/G polymorphism and HLA DRB1, which have been reported previously $(18,19)$.

\section{Statistical analysis}

Patients and controls were compared using allele-wise and genotype-wise Chi-square testing. Differences in distribution of age of disease onset were analyzed by the nonparametric Wilcoxon-Mann-Whitney test. All calculations were performed using BiAS software (Epsilon, Weinheim, Germany) (20).

Due to multiple comparisons we applied the Bonferroni adjustment (21). We divided the chosen overall significance level $(\alpha=0.05)$ by the number of hypotheses to be tested $(n=14)$, considering this value to be the significance level $\left(\alpha^{*}=0.0036\right)$ for any single comparison.

Power calculation for each group was performed assuming an allele frequency of $11.3 \%$ (derived from controls used in this study) and a type 1 error rate of $5 \%$. On the basis of these assumptions, we estimate that we have more than $80 \%$ power to detect an allelic odds ratio of 1.7 (T1D), 1.9 (Addison's disease) and 2 (Hashimoto's thyroiditis) for disease susceptibility in the case/control data set by using the program Power and Sample Size Calculations 2.1.30 (22).

The magnitude of associations was assessed using the odds ratio (OR) statistics. Confidence intervals (CI) were calculated for the OR by Woolf's method (23).

\section{Results}

No deviations from Hardy-Weinberg equilibrium were observed for PTPN22 $1858 \mathrm{C} / \mathrm{T}$ genotypes in controls or in any of the patient groups (Table 1).

\section{Type 1 diabetes mellitus}

Our results, given in Table 1, confirm that PTPN22 $1858 \mathrm{~T}$ is associated with T1D in the German population. Genotypes and allele frequencies show significant differences between patients with T1D and healthy controls $(P=0.0027$ and $P=0.0009$ respectively). 1858T was observed more often in T1D patients $(19.3 \%$ vs $11.3 \%, P=0.0009$; OR for allele $\mathrm{T}=1.88$, $95 \%$ CI [1.3-2.7]). These data are consistent with previously published studies in other populations $(13,15)$.

A sex-stratified analysis reveals an interesting new observation (Table 2): comparison of female patients with female controls shows a significant difference in their genotype distribution $(P=0.0003$; OR for allele $\mathrm{T}=3.12$, 95\% CI [1.7-5.6]), whereas no significant difference was detected between patients and controls of the male sex. No sex-related differences were observed for the allele distribution within our controls.

Rigorous Bonferroni correction showed no statistically significant associations between T1D and other factors such as age at onset, HLA DRB1 or CTLA-4 variants (Table 3).

\section{Addison's disease}

We found no evidence for an association of $1858 \mathrm{~T}$ with Addison's disease. Both genotypes and allele frequencies of patients and controls were similar $(11.6 \%$ vs $11.3 \%, P=0.9879$; OR for allele $\mathrm{T}=1.03,95 \% \mathrm{CI}$ [0.63-1.67]). No sex-related differences were observed.

\section{Hashimoto's thyroiditis}

Patients with Hashimoto's thyroiditis showed no significant difference in the distribution of the allele $\mathrm{T}$ to controls $(15.4 \%$ vs $11.3 \%, P=0.1863$; OR for allele $\mathrm{T}=1.43, \quad 95 \% \quad$ CI $[0.88-2.33])$. Furthermore, no sex-related differences were detected.

Table 2 Sex-related distribution of the PTPN22 1858 C/T polymorphism in German healthy controls and patients with type 1 diabetes mellitus.

\begin{tabular}{|c|c|c|c|c|c|c|c|c|}
\hline & \multicolumn{4}{|c|}{ Male } & \multicolumn{4}{|c|}{ Female } \\
\hline & \multicolumn{2}{|c|}{$\begin{array}{l}\text { Controls } \\
(n=116)\end{array}$} & \multicolumn{2}{|c|}{$\begin{array}{c}\text { Type } 1 \text { diabetes } \\
\quad(n=105)\end{array}$} & \multicolumn{2}{|c|}{$\begin{array}{c}\text { Controls } \\
(n=93)\end{array}$} & \multicolumn{2}{|c|}{$\begin{array}{c}\text { Type } 1 \text { diabetes } \\
\quad(n=115)\end{array}$} \\
\hline & $n$ & $\%$ & $n$ & $\%$ & $n$ & $\%$ & $n$ & $\%$ \\
\hline \multicolumn{9}{|l|}{ Genotypes } \\
\hline $\mathrm{CC}$ & 91 & 78.4 & 76 & 72.4 & 76 & 81.7 & 66 & 57.4 \\
\hline CT & 23 & 19.8 & 28 & 26.7 & 17 & 18.3 & 43 & 37.4 \\
\hline TT & 2 & 1.7 & 1 & 1.0 & 0 & 0.0 & 6 & 5.2 \\
\hline$P^{1}$ & \multicolumn{4}{|c|}{0.4432} & & & \multicolumn{2}{|c|}{0.0003} \\
\hline \multicolumn{9}{|l|}{ Allele } \\
\hline C & 205 & 88.4 & 180 & 85.7 & 169 & 90.9 & 175 & 76.1 \\
\hline $\mathrm{T}$ & 27 & 11.6 & 30 & 14.3 & 17 & 9.1 & 55 & 23.9 \\
\hline$P^{1}$ & \multirow{2}{*}{\multicolumn{4}{|c|}{$\begin{array}{c}0.4918 \\
1.27[0.7-2.2]\end{array}$}} & & & \multirow{2}{*}{\multicolumn{2}{|c|}{$\begin{array}{c}0.0001 \\
3.12[1.7-5.6]\end{array}$}} \\
\hline OR $[95 \% \mathrm{CI}]^{2}$ & & & & & & & & \\
\hline
\end{tabular}

${ }^{1}$ Compared with controls; ${ }^{2}$ odds ratio for the T allele compared with controls $[\mathrm{Cl}$, confidence interval]. 
Table 3 Distribution of clinical and genetic parameters among patients with type 1 diabetes stratified by the presence of the PTPN22 T allele.

\begin{tabular}{lccrr}
\hline Parameter & $\boldsymbol{n}$ & PTPN22 T (+) & PTPN22 (-) & $\boldsymbol{P}$ \\
\hline DRB1*03 present & 218 & $49(34.5 \%)$ & $79(31.0 \%)$ & $0.4712 \dagger$ \\
DRB1*04 present & 218 & $54(38.0 \%)$ & $105(41.1 \%)$ & $0.5395 \dagger$ \\
CTLA4 49 G present & 219 & $56(72.7 \%)$ & $98(69.0 \%)$ & $0.6749 \dagger$ \\
Age of onset in years (median, lower-upper quartile) & 138 & $10(6-15)$ & $9(5-13)$ & $0.2318 \ddagger$ \\
\hline
\end{tabular}

$n$, number of subjects available for analysis; the PTPN22 T(+) group contained T/T and C/T genotypes, whereas the PTPN22 T $(-)$ group comprised C/C homozygotes.

$\dagger x^{2}$-test; $\ddagger$ Wilcoxon-Mann-Whitney test.

\section{Discussion}

In the present study, we investigated the PTPN22 1858 $\mathrm{C} / \mathrm{T}$ polymorphism in susceptibility to type 1 diabetes mellitus, Hashimoto's thyroiditis and Addison's disease, in an attempt to corroborate the general role of PTPN22 as a susceptibility locus for these diseases in the German population. The reported association between PTPN22 $1858 \mathrm{~T}$ and both Addison's disease and Hashimoto's thyroiditis in other studies could not be verified by our analysis. This may be explained by different PTPN22 allele frequencies in several populations. For each of the patient groups (AD or HT), there is only one available study confirming the association. Velaga et al. investigated PTPN22 $1858 \mathrm{C} / \mathrm{T}$ genotypes of 104 patients with Addison's disease and found a significant increase in 1858T (17). Criswell et al. analyzed 194 patients with Hashimoto's thyroiditis selected from multiplex families with other autoimmune disease such as rheumatoid arthritis or multiple sclerosis among others (15). Thereby, these diseases (T1D, RA, GD or SLE) $(10,12,15,16)$ contributed to an accumulation of a higher immunogenetic risk within these families. Due to the small number of analyzed patients with AD or HT, we cannot exclude the possibility that subtle effects of the PTPN22 gene polymorphism may alter the genetic susceptibility of these diseases in the German population.

In accordance with recent findings, our data show an association of $1858 \mathrm{~T}$ with T1D in the German population. However, this susceptibility factor proved to be unique to the female sex, which is a novel observation. Smyth et al. evaluated the distribution of $1858 \mathrm{C} / \mathrm{T}$ genotypes on the basis of sex in 1600 T1D subjects and about 2000 families (14). Absolutely no effect of patient sex was observed in the large family-based cohort from Great Britain, Northern Ireland, USA and Romania $(P=0.951)$. However, in T1D subjects the obtained $P$ value was of borderline significance for the patient sex $(P=0.029)(14)$. Given that allelic frequencies vary in each population, this discrepancy and also the inconsistency of the present study with the findings of Smyth et al. may be attributed to population stratification. Nevertheless, we cannot exclude the possibility that this effect in our study may be caused by the smaller sample size in comparison with that of Smyth et al. (14).

Sex-specific differences in the genetic susceptibility to type 1 diabetes have been reported for HLA DQ locus and early disease onset or its seasonality for males (24). Furthermore, a male/female bias has been observed for HLA DR3/non DR4 patients (25) that can only be explained by an X-chromosomal linked inheritance of an additional interacting susceptibility factor (26). Little is known, however, about the contribution of genetics to sex differences in autoimmune diseases. So far, steroidal hormones are considered to be the primary mediators of sex differences. This assumption has been borne out by the increased prevalence of autoimmune diseases in women, the sexual dimorphism of the immune response and in vitro modulatory effects of sex steroids on immune functions. Their genetic effects most probably operate at the level of the steroid receptors that may act as transcription factors for susceptibility genes such as MHC or even PTPN22. However, the role of sex hormones in regulating these genes is not known. Sex hormones may act as critical modulatory factors that can induce disease expression or not (27). In particular, fine-tuning of T-lymphocyte is regulated by estrogens that augment the expression of FoxP 3 in murine T-cells and can drive the proliferation of $\mathrm{CD}^{+}$and $\mathrm{CD} 25^{+}$regulatory T-lymphocytes (28). Given that females have higher absolute numbers of $\mathrm{CD}^{+}{ }^{+}$-lymphocytes and higher levels of Th1 cytokines with a subsequently increased immune response (27), PTPN22 1858T could drive immunity in females to the development of type 1 diabetes by a sex-specific mechanism that remains to be elucidated.

\section{Acknowledgements}

This work was made possible by the funding of the European Foundation for the Study of Diabetes (EFSD).

\section{References}

1 Winqvist O, Soderbergh A \& Kampe O. The autoimmune basis of adrenocortical destruction in Addison's disease. Molecular Medicine Today 19962 282-289. 
2 Weetman AP. Cellular immune responses in autoimmune thyroid disease. Clinical Endocrinology 200461 405-413.

3 Mandrup-Poulsen T. Beta cell death and protection. Annals of the New York Academy of Sciences $2003100532-42$.

4 Weetman AP, Zhang L, Tandon N \& Edwards OM. HLA associations with autoimmune Addison's disease. Tissue Antigens $19913831-33$.

5 Yu L, Brewer KW, Gates S, Wu A, Wang T, Babu SR, Gottlieb PA, Freed BM, Noble J, Erlich HA, Rewers MJ \& Eisenbarth GS. DRB1*04 and DQ alleles: expression of 21-hydroxylase autoantibodies and risk of progression to Addison's disease. Journal of Clinical Endocrinology and Metabolism 199984 328-335.

6 Huang W, Connor E, Rosa TD, Muir A, Schatz D, Silverstein J, Crockett S, She JX \& Maclaren NK. Although DR3-DQB1*0201 may be associated with multiple component diseases of the autoimmune polyglandular syndromes, the human leukocyte antigen DR4-DQB1*0302 haplotype is implicated only in beta-cell autoimmunity. Journal of Clinical Endocrinology and Metabolism 1996 $812559-2563$.

7 Maclaren NK \& Riley WJ. Inherited susceptibility to autoimmune Addison's disease is linked to human leukocyte antigens-DR3 and/or DR4, except when associated with type I autoimmune polyglandular syndrome. Journal of Clinical Endocrinology and Metabolism $1986 \mathbf{6 2} 455-459$.

8 Donner H, Braun J, Seidl C, Rau H, Finke R, Ventz M, Walfish PG, Usadel KH \& Badenhoop K. Codon 17 polymorphism of the cytotoxic T lymphocyte antigen 4 gene in Hashimoto's thyroiditis and Addison's disease. Journal of Clinical Endocrinology and Metabolism $1997824130-4132$.

9 Kemp EH, Ajjan RA, Husebye ES, Peterson P, Uibo R, Imrie H, Pearce SH, Watson PF \& Weetman AP. A cytotoxic T lymphocyte antigen-4 (CTLA-4) gene polymorphism is associated with autoimmune Addison's disease in English patients. Clinical Endocrinology $199849609-613$.

10 Bottini N, Musumeci L, Alonso A, Rahmouni S, Nika K, Rostamkhani M, MacMurray J, Meloni GF, Lucarelli P, Pellecchia M, Eisenbarth GS, Comings D \& Mustelin T. A functional variant of lymphoid tyrosine phosphatase is associated with type I diabetes. Nature Genetics 200436 337-338.

11 Cohen S, Dadi H, Shaoul E, Sharfe N \& Roifman CM. Cloning and characterization of a lymphoid-specific, inducible human protein tyrosine phosphatase. Lyp. Blood 199993 2013-2024.

12 Begovich AB, Carlton VE, Honigberg LA, Schrodi SJ, Chokkalingam AP, Alexander HC, Ardlie KG, Huang Q, Smith AM, Spoerke JM, Conn MT, Chang M, Chang SY, Saiki RK, Catanese JJ, Leong DU, Garcia VE, McAllister LB, Jeffery DA, Lee AT, Batliwalla F, Remmers E, Criswell LA, Seldin MF, Kastner DL, Amos CI, Sninsky JJ \& Gregersen PK. A missense single-nucleotide polymorphism in a gene encoding a protein tyrosine phosphatase (PTPN22) is associated with rheumatoid arthritis. American Journal of Human Genetics $2004 \mathbf{7 5}$ $330-337$.

13 Siminovitch KA. PTPN22 and autoimmune disease. Nature Genetics $2004361248-1249$.

14 Smyth D, Cooper JD, Collins JE, Heward JM, Franklyn JA, Howson JM, Vella A, Nutland S, Rance HE, Maier L, Barratt BJ, Guja C, Ionescu-Tirgoviste C, Savage DA, Dunger DB, Widmer B, Strachan DP, Ring SM, Walker N, Clayton DG, Twells RC, Gough SC \& Todd JA. Replication of an association between the lymphoid tyrosine phosphatase locus (LYP/PTPN22) with type 1 diabetes, and evidence for its role as a general autoimmunity locus. Diabetes 200453 3020-3023.

15 Criswell LA, Pfeiffer KA, Lum RF, Gonzales B, Novitzke J, Kern M, Moser KL, Begovich AB, Carlton VE, Li W, Lee AT, Ortmann W, Behrens TW \& Gregersen PK. Analysis of families in the multiple autoimmune disease genetics consortium (MADGC) collection: the PTPN22 620W allele associates with multiple autoimmune phenotypes. American Journal of Human Genetics $2005 \mathbf{7 6}$ $561-571$.

16 Kyogoku C, Langefeld CD, Ortmann WA, Lee A, Selby S, Carlton VE, Chang M, Ramos P, Baechler EC, Batliwalla FM, Novitzke J, Williams AH, Gillett C, Rodine P, Graham RR, Ardlie KG, Gaffney PM, Moser KL, Petri M, Begovich AB, Gregersen PK \& Behrens TW. Genetic association of the R620W polymorphism of protein tyrosine phosphatase PTPN22 with human SLE. American Journal of Human Genetics $2004 \mathbf{7 5}$ 504-507.

17 Velaga MR, Wilson V, Jennings CE, Owen CJ, Herington S, Donaldson PT, Ball SG, James RA, Quinton R, Perros P \& Pearce SH. The codon 620 tryptophan allele of the lymphoid tyrosine phosphatase (LYP) gene is a major determinant of Graves' disease. Journal of Clinical Endocrinology and Metabolism 200489 5862-5865.

18 Donner H, Rau H, Walfish PG, Braun J, Siegmund T, Finke R, Herwig J, Usadel KH \& Badenhoop K. CTLA4 alanine-17 confers genetic susceptibility to Graves' disease and to type 1 diabetes mellitus. Journal of Clinical Endocrinology and Metabolism 1997 82 143-146.

19 Donner H, Seidl C, Van der Auwera B, Braun J, Siegmund T, Herwig J, Weets I, Usadel KH \& Badenhoop K. HLA-DRB1*04 and susceptibility to type 1 diabetes mellitus in a German/Belgian family and German case-control study. The Belgian Diabetes Registry. Tissue Antigens $200055271-274$.

20 Ackermann H. Der Chi2-Vierfelder-Test. In Biometrie, edn 3, ch 5 . pp 75-79. Ed. Hochheim. Darmstadt, 1999.

21 Bland JM \& Altman DG. Multiple significance tests: the Bonferroni method. British Medical Journal 1995310170.

22 Dupont WD \& Plummer WD. PS power and sample size program available for free on the Internet. Controlled Clinical Trials 1997 18274.

23 Woolf B. On estimating the relation between blood group and disease. Annals of Human Genetics $195519251-253$.

24 Weets I, Kaufman L, Van der Auwera B, Crenier L, Rooman RP, De Block C, Casteels K, Weber E, Coeckelberghs M, Laron Z, Pipeleers DG \& Gorus FK. Belgian Diabetes Registry. Seasonality in clinical onset of type 1 diabetes in Belgian patients above the age of 10 is restricted to HLA-DQ2/DQ8-negative males, which explains the male-to-female excess in incidence. Diabetologia $200447614-621$.

25 Cucca F, Goy JV, Kawaguchi Y, Esposito L, Merriman ME, Wilson AJ, Cordell HJ, Bain SC \& Todd JA. A male-female bias in type 1 diabetes and linkage to chromosome Xp in MHC HLADR3-positive patients. Nature Genetics $199819301-302$.

26 Contu D, Morelli L, Zavattari P, Lampis R, Angius E, Frongia P. Murru D, Maioli M, Francalacci P, Todd JA \& Cucca F. Sex-related bias and exclusion mapping of the nonrecombinant portion of chromosome $\mathrm{Y}$ in human type 1 diabetes in the isolated founder population of Sardinia. Diabetes $2002513573-3576$.

27 Whitacre CC. Sex differences in autoimmune disease. Nature Immunology 20012 777-780.

28 Polanczyk M, Carson BD, Subramanian S, Afentoulis M, Vandenbark AA, Ziegler SF \& Offner H. Cutting edge: estrogen drives expansion of the $\mathrm{CD} 4+\mathrm{CD} 25+$ regulatory $\mathrm{T}$ cell compartment. Journal of Immunology $20041732227-2230$.

Received 11 July 2005

Accepted 1 September 2005 